\title{
Chronic kidney disease, 24-h blood pressure and small vessel diseases are independently associated with cognitive impairment in lacunar infarct patients
}

\author{
Yasumasa Yamamoto ${ }^{1}$, Tomoyuki Ohara ${ }^{1}$, Yoshinari Nagakane ${ }^{1}$, Eijiro Tanaka ${ }^{1}$, Fukiko Morii ${ }^{1}$, \\ Takashi Koizumi $^{1}$ and Ichiro Akiguchi ${ }^{2}$
}

Although the relationships between chronic kidney disease (CKD) and cognitive impairment (CI) have been highlighted, the etiology of $\mathrm{Cl}$ in CKD remains uncertain. Subjects comprised 224 consecutive patients with symptomatic lacunar infarction who underwent magnetic resonance imaging and ambulatory blood pressure monitoring (ABPM). Diurnal blood pressure (BP) patterns were categorized into three groups: dippers, non-dippers and risers. Lacunar infarcts (LIs), including both symptomatic and silent and diffuse white matter lesions (WMLs), were graded into three grades according to their degree. The results of kidney function were evaluated using estimated glomerular filtration rate (eGFR), categorized into three groups: stage 1, >60; stage 2, 30-60; and stage $3,<30 \mathrm{ml} \mathrm{min}^{-1}$ per $1.73 \mathrm{~m}^{2}$. There were 44 patients with Cl. Confluent WMLs, including WML 2 and WML 3 , were found in 36 patients $(81.8 \%)$, and multiple lacunae including LI 2 and LI 3 were found in 30 patients (68.1\%) with $\mathrm{Cl}$. Age $>75$ years (odds ratio (OR), 5.5; $P<0.05$ ), male sex (OR, 2.8; $P<0.05$ ), non-dippers (OR, 6.3; $P<0.05)$ and risers (OR, 5.6; $P<0.05)$, eGFR $30-60 \mathrm{ml} \mathrm{min}^{-1}$ per $1.73 \mathrm{~m}^{2}(\mathrm{OR}, 2.9 ; \boldsymbol{P}<0.05)$ and eGFR $<30 \mathrm{ml} \mathrm{min}^{-1}$ per $1.73 \mathrm{~m}^{2}$ (OR, 23.8; $P<0.01$ ), WML grade 2 (OR, 5.1; $P<0.01$ ) and WML grade 3 (OR, 45.2; $P<0.001$ ) and LI grade 2 (OR, 3.2; $P<0.05)$ and $\mathrm{LI}$ grade 3 (OR, 6.4; $P<0.05$ ) were independently associated with $\mathrm{Cl}$. Age $>75$ years (OR, 4.1; $P<0.05)$, eGFR $30-60 \mathrm{ml} \mathrm{min}^{-1}$ per $1.73 \mathrm{~m}^{2}(0 \mathrm{R}, 3.7 ; P<0.05)$ and eGFR $<30 \mathrm{ml} \mathrm{min}^{-1}$ per $1.73 \mathrm{~m}^{2}(0 \mathrm{R}, 8.7 ; P<0.05)$ were independently associated with WML grade 3 . Extensive small vessel diseases, CKD and non-dipping status were independently associated with $\mathrm{Cl}$. CKD appears to mainly contribute to vascular $\mathrm{Cl}$, whereas possibilities of overlapping with other mechanisms such as degenerative $\mathrm{Cl}$ cannot be excluded. Strict night time BP control and renoprotective treatment may be warranted to prevent $\mathrm{Cl}$.

Hypertension Research (2011) 34, 1276-1282; doi:10.1038/hr.2011.118; published online 11 August 2011

Keywords: ambulatory blood pressure monitoring; non-dipper; chronic kidney disease; cognitive impairment; small vessel disease

\section{INTRODUCTION}

Chronic kidney disease $(\mathrm{CKD})$ is a growing public health problem ${ }^{1}$ and is emerging as an independent risk factor for not only cardiovascular events, but also stroke, cerebral small vessel diseases such as white matter lesions (WMLs) and lacunar infarcts (LIs) ${ }^{2-4}$ and cognitive impairment $(\mathrm{CI}) .^{5-11}$ An increased burden of cerebrovascular disease has been considered to explain the etiology of CI. ${ }^{5-13} \mathrm{Up}$ to now, however, only a few studies have applied structural brain imaging on the association between $\mathrm{CKD}$ and $\mathrm{CI},{ }^{13}$ leaving the etiology of $\mathrm{CI}$ in CKD uncertain.

On the other hand, elevated blood pressure (BP) has been established as the most important risk factor for cerebral small vessel disease. $^{14,15}$ Moreover, 24-h ambulatory BP monitoring (ABPM) correlates more closely with hypertensive target organ damage than casual office BP readings. ${ }^{16-19}$
The present study aimed to thoroughly elucidate associations between ABPM, cerebral small vessel disease and CKD with CI in a cohort of patients with LIs. LIs are lesions caused by penetrating artery disease associated with risk factors, natural history and clinical manifestation, which are significantly different from those of other brain infarcts. Consequently, they have homogeneous characteristics that are relevant and worthy of study.

\section{METHODS}

Patient selection

Among admissions to the Department of Neurology at the Kyoto Second Red Cross Hospital between 2002 and 2005, 245 consecutive patients with symptomatic lacunar infarction were selected for this study. We defined symptomatic lacunar infarction as a relevant deep, single hyperintensity, $\leqslant 20 \mathrm{~mm}$ in diameter on axial slices from magnetic resonance imaging (MRI) with 
diffusion-weighted imaging that corresponded to one of the lacunar syndromes. Patients who had a potential cardiac source of embolism and those who had $>50 \%$ stenosis of the extracranial carotid or vertebral arteries as detected by color-coded Duplex sonography were excluded. Among the 245 patients, 224 patients underwent 24-h BP monitoring, without previous administration of antihypertensive agents for $>2$ weeks after ictus. This study was reviewed by the ethics committee and all patients gave their informed consent to participate in this study.

\section{Conventional risk factors}

Hypertension was defined as either previous or present use of antihypertensive agents or a systolic BP (SBP) $>140 \mathrm{~mm} \mathrm{Hg}$ and/or a diastolic BP $>90 \mathrm{~mm} \mathrm{Hg}$ for $>2$ weeks from ictus without administration of antihypertensive agents. Diabetes mellitus was defined as a fasting glucose level of $>140 \mathrm{mg} \mathrm{dl}^{-1}$ or use of antidiabetic medication. Dyslipidemia was defined as a fasting total cholesterol level of $>220 \mathrm{mgdl}^{-1}$ and/or a fasting triglyceride level of $>200 \mathrm{mg} \mathrm{dl}^{-1}$ without administration of any antihyperlipidemic agents. Cigarette smoking was defined as regularly smoking at the time of stroke.

\section{Magnetic resonance imaging}

All patients underwent MRI and magnetic resonance angiography. MRI scans were performed using 1.5-T superconducting magnets (Gyroscan Intera
Achieva 1.5 Pulsar, Philips, Eintdhoven, Netherlands). Each MRI was performed within 3 days after ictus. Diffusion-weighted scans (TR: $1861 \mathrm{~ms} / \mathrm{TE}$ : $69 \mathrm{~ms}$, echo planar imaging factor: 37 ), T2-weighted scans (TR: $3500 \mathrm{~ms} / \mathrm{TE}$ : $100 \mathrm{~ms}$ ) and FLAIR were obtained at a slice thickness of $7 \mathrm{~mm}$.

Silent LIs were defined as small deep infarcts $\leqslant 15 \mathrm{~mm}$ in diameter on horizontal sections, with high intensity on T2-weighted and FLAIR imaging located within the basal ganglia, thalamus, internal capsule, corona radiata or pons. WMLs were defined as diffuse hyperintensities located in the periventricular and/or subcortical white matter on T2-weighted and FLAIR imaging. The number of lacunae were counted and graded as follows: grade 1, single lacunae; grade 2, two to five lacunae; and grade 3, more than five lacunae. Diffuse WMLs were graded referring to Schmidt's classification: $:^{20}$ grade 1 , absent or punctuate; grade 2 , becoming confluent; and grade 3, confluent. Results of MRI were evaluated by two authors (YY and IA) who were blinded to both BP data and clinical findings.

\section{Ambulatory blood pressure monitoring}

Data for 24-h BP were recorded using a portable automatic recorder (ABPM TM-243, A\&D CompanyTokyo, Japan) at 30-min intervals over a 24-h period from 1300 to 1300 hours the following day. The accuracy of the equipment had been previously established. ${ }^{21}$ ABPM was performed 2-4 weeks after symptomatic LI ictus without antihypertensive therapy. Average BP values were calculated as follows. Systolic and diastolic BP were averaged over

Table 1 Baseline characteristics in the three groups

\begin{tabular}{|c|c|c|c|c|c|}
\hline & Non-demented & $\mathrm{MCl}$ & $\begin{array}{c}\text { P-value, } \\
\text { non-demented vs. } \mathrm{MCl}\end{array}$ & $\mathrm{Cl}$ & $\begin{array}{c}\text { P-value, } \\
\text { non-demented vs. Cl}\end{array}$ \\
\hline Number & 159 & 21 & & 44 & \\
\hline Age & $68.3 \pm 9.4$ & $72.4 \pm 7.5$ & 0.058 & $74.0 \pm 8.5$ & 0.0003 \\
\hline Sex (male) & $96(60.3)$ & $10(47.6)$ & 0.23 & $28(63.6)$ & 0.57 \\
\hline Hypertension & $124(77.9)$ & $18(85.7)$ & 0.41 & $40(90.9)$ & 0.063 \\
\hline Diabetes mellitus & $27(16.9)$ & $5(23.8)$ & 0.44 & $4(9.09)$ & 0.2 \\
\hline Dyslipidemia & $41(25.7)$ & $8(30.0)$ & 0.23 & $12(27.2)$ & 0.84 \\
\hline Smoking & $38(23.8)$ & $4(19.0)$ & 0.56 & $12(27.2)$ & 0.57 \\
\hline Casual SBP & $145.2 \pm 20.8$ & $151.4 \pm 19.3$ & 0.12 & $151.3 \pm 20.1$ & 0.075 \\
\hline 24-h SBP & $142.9 \pm 21.0$ & $148.5 \pm 21.2$ & 0.24 & $151.0 \pm 19.6$ & 0.021 \\
\hline Nocturnal SBP dip & $0.048 \pm 0.082$ & $0.043 \pm 0.075$ & 0.79 & $0.008 \pm 0.071$ & 0.0032 \\
\hline Casual DBP & $82.1 \pm 12.3$ & $81.0 \pm 13.3$ & 0.68 & $83.6 \pm 13.4$ & 0.61 \\
\hline 24-h DBP & $80.1 \pm 11.9$ & $82.0 \pm 14.2$ & 0.5 & $79.8 \pm 12.8$ & 0.89 \\
\hline Nocturnal DBP dip & $0.067 \pm 0.092$ & $0.053 \pm 0.085$ & 0.49 & $0.037 \pm 0.082$ & 0.052 \\
\hline Dipper & $34(21.3)$ & $6(6.8)$ & & $3(6.8)$ & \\
\hline Non-dipper & $75(47.1)$ & $8(38.0)$ & 0.64 & $21(47.7)$ & 0.076 \\
\hline Riser & $44(27.6)$ & 7 (33.3) & 0.86 & $20(45.5)$ & 0.013 \\
\hline Extreme dipper & $6(3.7)$ & 0 & 0.97 & 0 & 0.97 \\
\hline Proteinuria & $24(15.0)$ & $10(47.6)$ & 0.0009 & $18(40.9)$ & 0.0003 \\
\hline eGFR $\left(\mathrm{m} / \mathrm{min}^{-1}\right.$ per $\left.1.73 \mathrm{~m}^{2}\right)$ & $64.5 \pm 17.9$ & $58.4 \pm 22.2$ & 0.16 & $49.5 \pm 19.6$ & $<0.0001$ \\
\hline eGFR > 90 & $12(7.5)$ & $2(9.5)$ & & $1(2.27)$ & \\
\hline eGFR 60-89 & $81(50.9)$ & $7(33.3)$ & 0.44 & $10(22.7)$ & 0.78 \\
\hline eGFR 30-59 & $64(40.2)$ & $11(52.3)$ & 0.97 & $28(63.6)$ & 0.11 \\
\hline eGFR 15-29 & $2(1.2)$ & 0 & 0.97 & $4(9.0)$ & 0.97 \\
\hline eGFR $<15$ & 0 & $1(4.7)$ & & $1(2.2)$ & \\
\hline \multicolumn{6}{|l|}{ Lacunar infarcts } \\
\hline Grade 1 & $114(71.6)$ & $8(38.0)$ & & $14(31.8)$ & \\
\hline Grade 2 & $35(22.0)$ & $11(52.3)$ & 0.0054 & $21(47.7)$ & 0.0002 \\
\hline Grade 3 & $6(3.7)$ & $2(9.5)$ & 0.081 & $9(20.4)$ & $<0.0001$ \\
\hline \multicolumn{6}{|l|}{ White matter lesions } \\
\hline Grade 1 & $119(74.8)$ & $6(28.5)$ & & $8(18.1)$ & \\
\hline Grade 2 & $6(27.2)$ & $14(66.6)$ & 0.0012 & $18(40.9)$ & 0.0003 \\
\hline Grade 3 & $6(3.3)$ & $1(4.7)$ & 0.16 & $18(40.9)$ & $<0.0001$ \\
\hline MMSE & $29.5 \pm 0.80$ & $26.2 \pm 0.73$ & $<0.0001$ & $19.5 \pm 3.8$ & $<0.0001$ \\
\hline
\end{tabular}

Abbreviations: $\mathrm{Cl}$, cognitive impairment; DBP, diastolic blood pressure; eGFR, estimated glomerular filtration rate; MCI, mild cognitive impairment; MMSE, mini-mental state examination; SBP, systolic blood pressure.

Values in parentheses are percentage.

$P$-values are calculated compared with non-demented group. 
successive 30 -min intervals for daytime (0600 to 2200 hours) and night time ( 2230 to 0530 hours) periods. The degree of nocturnal BP dip was calculated as follows: (average daytime value-average night time BP)/average daytime value.

Based on the BP dip, patients were categorized as dippers when the BP dip was $>0.1$ and patients were categorized as non-dippers when the BP dip was $0.1-0$. Furthermore, patients were categorized as extreme dippers when the BP dip was $>0.25$ and risers when the BP dip was $<0$. According to the guideline, 24-h SBP average values were categorized into three groups: $<125 \mathrm{~mm} \mathrm{Hg}$, $125-145 \mathrm{~mm} \mathrm{Hg}$ and $>145 \mathrm{~mm} \mathrm{Hg}$.

\section{Chronic kidney disease}

The estimated glomerular filtration rate (eGFR) was calculated from the serum creatinine $(\mathrm{Cr})$ value and age using the abbreviated Modification of Diet in Renal Disease equation modified by the Japanese coefficient, ${ }^{22}$ as follows: eGFR $\left(\mathrm{ml} \mathrm{min}^{-1}\right.$ per $\left.1.73 \mathrm{~m}^{2}\right)=0.741 \times 175 \times \mathrm{age}^{-0.203} \times \mathrm{Cr}\left(\mathrm{mg} \mathrm{dl}^{-1}\right)^{-1.154}($ if female,

Table 2 The relationship between diurnal blood pressure pattern and categorized estimated glomerular filtration rate (eGFR)

\begin{tabular}{lccc} 
& eGFR $>60$ & eGFR 30-60 & $e G F R<30$ \\
& 113 & 103 & 8 \\
\hline $\begin{array}{l}\text { Dipper } \\
49 \\
\text { Non-dipper } \\
104 \\
\text { Riser } \\
71\end{array}$ & $26(53.0)$ & $22(44.8)$ & $1(2.0)$ \\
\hline
\end{tabular}

$\times 0.742$ ). Then, eGFR was categorized into three groups: stage $1,>60$; stage 2 , 45-60; and stage $3,<45 \mathrm{ml} \mathrm{min}^{-1}$ per $1.73 \mathrm{~m}^{2}$.

Based on Japanese CKD stage criteria, eGFR values were classified into five groups: $\geqslant 90,60-89,30-59,15-29$ and $<15 \mathrm{ml} \mathrm{min}^{-1}$ per $1.73 \mathrm{~m}^{2}$.

Proteinuria was detected by qualitative analysis of proteinuria.

Evaluation of global cognitive impairment (GCI)

The cognitive ability of all patients was also evaluated using the mini-mental state examination (MMSE). As the standard MMSE cut score of 24 has been widely used, we diagnosed CI if MMSE score was $\leqslant 24 .{ }^{23}$ Moreover, as a cut score of 27 was proposed for mild CI (MCI), we diagnosed MCI if MMSE score was $25-27 .{ }^{24}$ We estimated MMSE of $>27$ as non-demented.

\section{Statistical analysis}

First, demographics, conventional risk factors, categorized eGFR, 24-h SBP average, diurnal BP pattern and the three categories for the degree of small vessel disease were compared between groups with $\mathrm{MCI}$ and $\mathrm{CI}$ and nondemented estimating non-demented group as reference. Continuous variables were expressed as mean \pm s.d., and categorized variables were given as the percentage of patients so affected. A comparison of clinical variables between groups was performed with the $\chi^{2}$-test for categorized variables and with Student's $t$-test for continuous variables. For groups with three graded small vessel disease, grade 1 was estimated as the reference.

The relationship between CKD and ABPM pattern were also investigated using the $\chi^{2}$-test.

Logistic regression analysis 1 was performed to investigate the factors contributing to groups with $\mathrm{MCI}$ and CI. As the number of extreme dippers was small and their characteristics were similar to dippers (Table 1), extreme dippers were incorporated into dippers. Similarly, eGFR $<15$ and $>90 \mathrm{mlmin}^{-1}$ per $1.73 \mathrm{~m}^{2}$ were incorporated into eGFR $15-30$ and

Table 3 Contributing factors for mild cognitive impairment

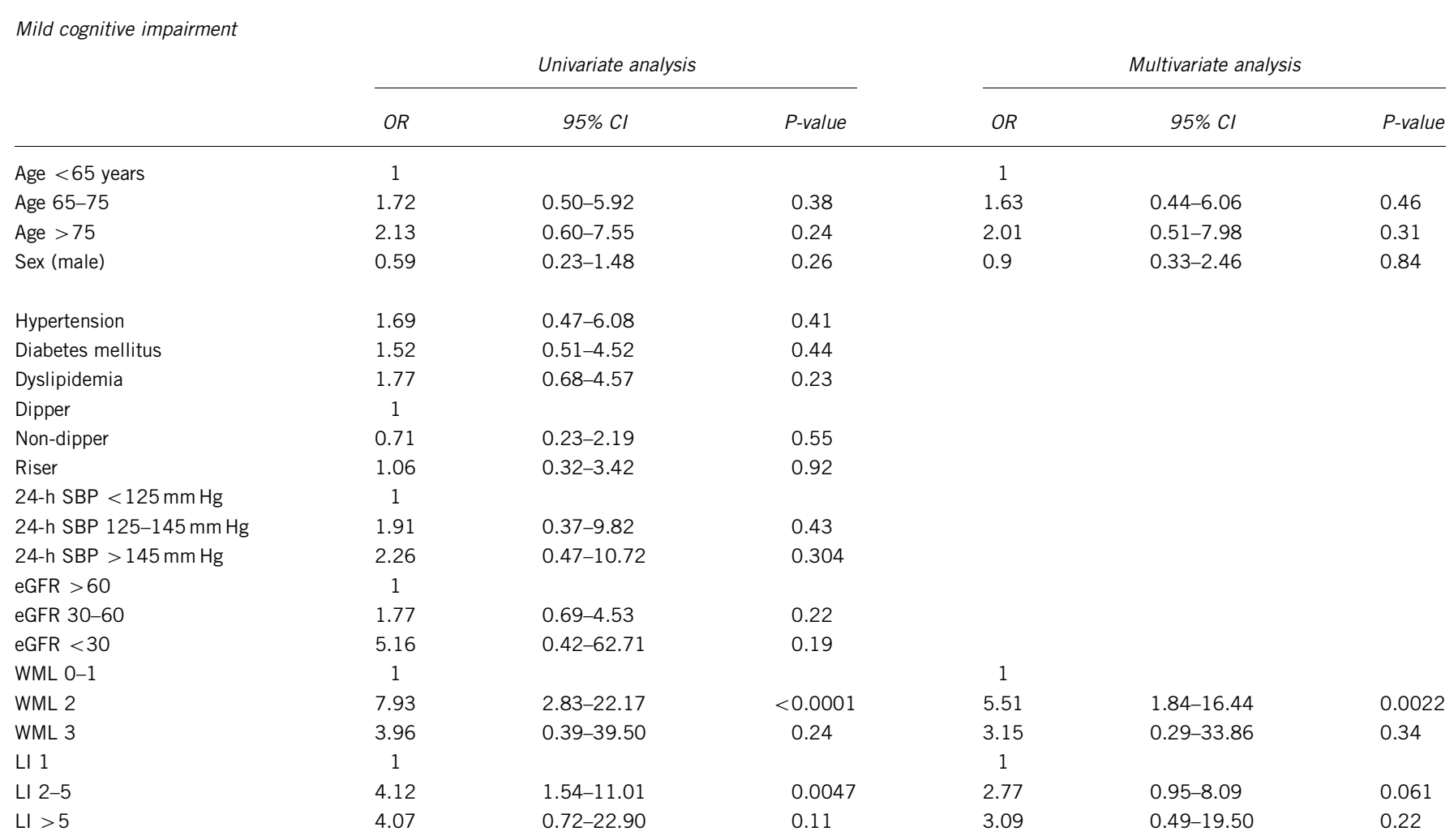

Abbreviations: $\mathrm{Cl}$, confidence interval; eGFR, estimated glomerular filtration rate; LI, lacunar infarct; OR, odds ratio; SBP, systolic blood pressure, WML, white matter lesion.

$\mathrm{OR}$ and $95 \% \mathrm{Cls}$ of various covariates for the mild cognitive impairment group. 
$60-90 \mathrm{ml} \mathrm{min}^{-1}$ per $1.73 \mathrm{~m}^{2}$, respectively. The odds ratio (OR) and $95 \%$ confidence intervals of covariates for the groups with $\mathrm{MCI}$ and $\mathrm{CI}$ were calculated. Covariates included were conventional risk factors (yes or no) and categorized groups, such as 24-h SBP average (125-145 and $145 \mathrm{~mm} \mathrm{Hg} v s$. $<125 \mathrm{~mm} \mathrm{Hg}$ ), ABPM pattern (non-dippers and risers $v$ s. dippers), eGFR (eGFR $<30$ and $30-60 v$ s. eGFR $>60 \mathrm{ml} \mathrm{min}^{-1}$ per $1.73 \mathrm{~m}^{2}$ ), WML and LI (grade 2 and grade $3 v s$. grade 1). ABPM pattern was adjusted for categorized 24-h SBP average. Covariates shown to be significant in univariate analysis were subsequently examined using multivariate analysis.

Logistic regression analysis 2 was performed to explore the association of the aforementioned covariates with extensive small vessel disease using logistic regression analysis, estimating grade 1 for $\mathrm{LI}$ and WML as a reference. The ORs for multiple lacunae (grade 2 and grade 3 vs. grade 1) and confluent WMLs (grade 2 and grade $3 v s$. grade 1) were calculated. Logistic regression analysis was performed using Stat-View 5.0 software (SAS Institute, Cary, NC, USA). Probability values $<0.05$ were considered significant.

\section{RESULTS}

\section{Baseline characteristics}

CI was absent in 159 patients and MCI was present in 21 patients and $\mathrm{CI}$ in 44 patients (Table 1). Compared with the non-demented group I, the group with MCI showed higher incidence of proteinuria and more extensive small vessel disease, and the group with CI showed older age, higher 24-h SBP average, lower nocturnal SBP dip, lower eGFR and more extensive small vessel disease (Table 1). In the MCI group, confluent WMLs including WML grade 2 and WML grade 3 were found in 15 patients (71.3\%), and multiple lacunae including LI grade 2 and LI grade 3 were found in 13 patients $(61.8 \%)$. In the CI group, confluent WMLs were found in 36 patients $(81.8 \%)$, and multiple lacunae in 30 patients $(68.1 \%)$. Statin was used for 78 patients (34.8\%) and antiplatelet agents were prescribed for 214 patients $(95.5 \%)$. There were no significant differences between groups (data not shown).

\section{The relationship between CKD and diurnal BP pattern}

There were no significant relationships between categorized CKD and diurnal BP pattern (Table 2).

Logistic regression analysis 1: factors Associated with $M C I$ and CI. The OR and 95\% confidence intervals of covariates for MCI and CI are displayed in Tables 3 and 4 . The covariate significantly associated with MCI after multivariate analysis was WML grade $2(\mathrm{OR}, 5.5 ; P<0.05)$. The covariates significantly associated with $\mathrm{CI}$ after multivariate analysis were age $>75$ years $(\mathrm{OR}, 5.5 ; P<0.05)$, male sex $(\mathrm{OR}, 2.8$; $P<0.05)$, non-dippers (OR, 6.3; $P<0.05)$ and risers (OR, 5.6; $P<0.05)$, eGFR $30-60 \mathrm{ml} \mathrm{min}^{-1}$ per $1.73 \mathrm{~m}^{2}(\mathrm{OR}, 2.9 ; P<0.05)$ and eGFR $<30 \mathrm{ml} \mathrm{min}^{-1}$ per $1.73 \mathrm{~m}^{2}$ (OR, 23.8; $P<0.01$ ), WML grade 2 $(\mathrm{OR}, 5.1 ; P<0.01)$ and $\mathrm{WML}$ grade $3(\mathrm{OR}, 45.2 ; P<0.001)$ and $\mathrm{LI}$ grade $2(\mathrm{OR}, 3.2 ; P<0.05)$ and $\mathrm{LI}$ grade $3(\mathrm{OR}, 6.4 ; P<0.05)$.

Logistic regression analysis 2: factors associated with extensive small vessel disease. The OR and 95\% confidence intervals of covariates for confluent WMLs and multiple lacunae are displayed in Tables 5 and 6. In multivariate analysis, age $>75$ years $(\mathrm{OR}, 2.3 ; P<0.05)$, female sex $(\mathrm{OR}, 0.53 ; P<0.05)$ and hypertension $(\mathrm{OR}, 5.46 ; P<0.05)$ were significantly associated with WML grade 2 , and age $>75$ years $(\mathrm{OR}$, $4.1 ; P<0.05)$, eGFR $30-60 \mathrm{ml} \mathrm{min}^{-1}$ per $1.73 \mathrm{~m}^{2}(\mathrm{OR}, 3.7 ; P<0.05)$

Table 4 Contributing factors for cognitive impairment

Cognitive impairment

\begin{tabular}{|c|c|c|c|c|c|c|}
\hline & & Univariate analy & & & Multivariate ana & \\
\hline & $O R$ & $95 \% \mathrm{Cl}$ & $\mathrm{P}$-value & OR & $95 \% \mathrm{Cl}$ & P-value \\
\hline Age $<65$ years & 1 & & & 1 & & \\
\hline Age 65-75 & 1.65 & $0.58-4.67$ & 0.33 & 1.62 & $0.42-6.22$ & 0.48 \\
\hline Age $>75$ & 4.43 & $1.67-11.79$ & 0.0028 & 5.55 & $1.48-20.74$ & 0.01 \\
\hline Sex (male) & 1.14 & $0.57-2.29$ & 0.69 & 2.82 & $1.02-7.75$ & 0.043 \\
\hline Hypertension & 2.82 & $0.94-8.43$ & 0.063 & & & \\
\hline Diabetes mellitus & 0.48 & $0.16-1.48$ & 0.205 & & & \\
\hline Dyslipidemia & 1.07 & $0.50-2.29$ & 0.84 & & & \\
\hline Dipper & 1 & & & 1 & & \\
\hline Non-dipper & 3.73 & $1.04-13.28$ & 0.041 & 6.37 & $1.16-34.80$ & 0.032 \\
\hline Riser & 6.01 & $1.67-21.95$ & 0.0061 & 5.6 & $1.00-31.21$ & 0.049 \\
\hline 24-h SBP $<125 \mathrm{~mm} \mathrm{Hg}$ & 1 & & & & & \\
\hline 24-h SBP 125-145 mm Hg & 1.5 & $0.43-5.15$ & 0.51 & 2.58 & $0.44-15.03$ & 0.29 \\
\hline 24-h SBP >145 mm Hg & 2.73 & $0.88-8.44$ & 0.81 & 3.74 & $0.72-19.48$ & 0.11 \\
\hline eGFR $>60$ & 1 & & & 1 & & \\
\hline eGFR 30-60 & 3.69 & $1.71-7.96$ & 0.0008 & 2.95 & $1.10-7.95$ & 0.031 \\
\hline eGFR $<30$ & 21.13 & $3.65-122.2$ & 0.0007 & 23.88 & $2.32-245.67$ & 0.0076 \\
\hline WML 0-1 & 1 & & & 1 & & \\
\hline WML 2 & 7.65 & $3.06-19.08$ & $<0.0001$ & 5.13 & $1.73-15.21$ & 0.0032 \\
\hline WML 3 & 53.55 & $15.77-181.83$ & $<0.0001$ & 45.26 & $9.75-210.07$ & $<0.0001$ \\
\hline LI 1 & 1 & & & 1 & & \\
\hline LI 2-5 & 4.5 & $2.08-9.71$ & 0.0001 & 3.27 & $1.19-9.66$ & 0.031 \\
\hline $\mathrm{LI}>5$ & 10.46 & $3.37-32.51$ & $<0.0001$ & 6.47 & $1.43-29.22$ & 0.015 \\
\hline
\end{tabular}

Abbreviations: $\mathrm{Cl}$, confidence interval; eGFR, estimated glomerular filtration rate; LI, lacunar infarct; OR, odds ratio; SBP, systolic blood pressure, WML, white matter lesion.

OR and $95 \% \mathrm{Cls}$ of various covariates for the cognitive impairment group. 


\begin{tabular}{|c|c|c|c|c|c|c|}
\hline & \multicolumn{3}{|c|}{ Univariate analysis } & \multicolumn{3}{|c|}{ Multivariate analysis } \\
\hline & $O R$ & $95 \% \mathrm{Cl}$ & P-value & $O R$ & $95 \% \mathrm{Cl}$ & P-value \\
\hline \multicolumn{7}{|l|}{ LI grade 2 vs. grade 1} \\
\hline Age $<65$ years & 1 & & & 1 & & \\
\hline Age 65-75 & 0.87 & $0.42-1.79$ & 0.71 & 0.71 & $0.32-1.52$ & 0.37 \\
\hline Age $>75$ & 0.71 & $0.34-1.49$ & 0.37 & 0.59 & $0.26-1.31$ & 0.19 \\
\hline Sex (male) & 0.75 & $0.42-1.35$ & 0.34 & 0.8 & $0.42-1.50$ & 0.8 \\
\hline Hypertension & 6.03 & $2.05-17.79$ & 0.0011 & 4.75 & $1.46-15.23$ & 0.0095 \\
\hline Diabetes mellitus & 1.51 & $0.70-3.23$ & 0.28 & & & \\
\hline Dyslipidemia & 0.69 & $0.35-1.36$ & 0.29 & & & \\
\hline Dipper & 1 & & & 1 & & \\
\hline Non-dipper & 1.63 & $0.75-3.71$ & 0.2 & 1.86 & $0.78-4.44$ & 0.16 \\
\hline Riser & 2.94 & $1.27-6.78$ & 0.011 & 3.21 & $1.28-8.06$ & 0.012 \\
\hline 24-h SBP $<125 \mathrm{~mm} \mathrm{Hg}$ & 1 & & & & & \\
\hline 24-h SBP $125-145 \mathrm{~mm} \mathrm{Hg}$ & 1.63 & $0.60-4.36$ & 0.33 & 0.94 & $0.30-2.89$ & 0.91 \\
\hline 24-h SBP > $145 \mathrm{~mm} \mathrm{Hg}$ & 2.36 & $0.93-5.94$ & 0.067 & 0.9 & $0.30-2.70$ & 0.86 \\
\hline eGFR > $>0$ & 1 & & & 1 & & \\
\hline eGFR 30-60 & 2.01 & $1.10-3.65$ & 0.022 & 1.55 & $0.82-2.96$ & 0.17 \\
\hline eGFR $<30$ & 7.14 & $1.31-38.92$ & 0.023 & 5.38 & $0.95-30.25$ & 0.055 \\
\hline \multicolumn{7}{|l|}{ LI grade 3 vs. grade 1} \\
\hline Age $<65$ & 1 & & & 1 & & \\
\hline Age 65-75 & 1.53 & $0.43-5.37$ & 0.5 & 1.59 & $0.43-5.90$ & 0.48 \\
\hline Age $>75$ & 0.65 & $0.15-2.79$ & 0.56 & 0.56 & $0.12-2.54$ & 0.45 \\
\hline Sex (male) & 1.13 & $0.39-3.25$ & 0.81 & 1.5 & $0.50-4.51$ & 0.46 \\
\hline Hypertension & 2.7 & $0.58-12.39$ & 0.2 & & & \\
\hline Diabetes mellitus & 1.32 & $0.34-5.02$ & 0.68 & & & \\
\hline Dyslipidemia & 1 & $0.33-3.02$ & $>0.99$ & & & \\
\hline Dipper & 1 & & & 1 & & \\
\hline Non-dipper & 5.34 & $0.65-43.84$ & 0.11 & 5.06 & $0.59-43.21$ & 0.13 \\
\hline Riser & 8.94 & $1.06-75.23$ & 0.043 & 8.5 & $0.96-74.68$ & 0.053 \\
\hline 24-h SBP $<125 \mathrm{~mm} \mathrm{Hg}$ & 1 & & & 1 & & \\
\hline 24-h SBP $125-145 \mathrm{~mm} \mathrm{Hg}$ & 0.72 & $0.15-3.49$ & 0.68 & 0.49 & $0.092-2.63$ & 0.4 \\
\hline 24-h SBP > 145 mm Hg & 1.28 & $0.32-5.04$ & 0.72 & 0.87 & $0.20-3.75$ & 0.85 \\
\hline eGFR $>60$ & 1 & & & 1 & & \\
\hline eGFR 30-60 & 3.25 & $1.07-9.91$ & 0.037 & 4.1 & $1.30-12.86$ & 0.015 \\
\hline eGFR $<30$ & 8 & $0.61-104.01$ & 0.112 & 7.67 & $0.53-110.03$ & 0.133 \\
\hline
\end{tabular}

Abbreviations: $\mathrm{Cl}$, confidence interval; eGFR, estimated glomerular filtration rate; LI, lacunar infarct; OR, odds ratio; SBP, systolic blood pressure.

$\mathrm{OR}$ and $95 \% \mathrm{Cls}$ of various covariates for the cognitive impairment group.

and eGFR $<30 \mathrm{ml} \mathrm{min}^{-1}$ per $1.73 \mathrm{~m}^{2}(\mathrm{OR}, 8.7 ; P<0.05)$ were significantly associated with WML grade 3. Hypertension (OR, 4.7; $P<0.001)$ and riser (OR, 3.2; $P<0.05)$ were significantly associated with LI grade 2, and eGFR $<30$ to $60 \mathrm{ml} \mathrm{min}^{-1}$ per $1.73 \mathrm{~m}^{2}$ (OR, 4.1; $P<0.05)$ was significantly associated with LI grade 3.

\section{DISCUSSION}

In groups with $\mathrm{MCI}$ and $\mathrm{CI}$, extensive small vessel diseases were frequently identified. Age $>75$ years, male sex, non-dipping status, CKD represented by eGFR $<60 \mathrm{ml} \mathrm{min}^{-1}$ per $1.73 \mathrm{~m}^{2}$, extensive small vessel diseases were found to be independently associated with $\mathrm{CI}$, whereas only extensive small vessel diseases (WML grade 2) were found to be independently associated with MCI. CKD was also independently associated with extensive small vessel diseases including WML grade 3 and LI grade 3.

The presence of extensive small vessel disease including severe WMLs (WML grade 3) and many lacunae (LI grade 3) were strongly associated with CI (ORs, 45.2 and 6.4, respectively) in multivariate analysis. Moreover, CKD was also independently asso- ciated with severe WMLs and many lacunae. Accordingly, the significant relationship between $\mathrm{CI}$ and $\mathrm{CKD}$ in the present study is partly explicable by the hypothesis that extensive small vessel disease may represent an intermediate stage along the pathway from CKD to GCI.

On the other hand, CKD was independently associated with CI after adjusting for extensive small vessel diseases. Unexpectedly, adjustment for confluent WMLs only slightly attenuated the OR of CKD for CI. Moreover, the association of CKD with CI was stronger than that with extensive small vessel disease. There is a growing awareness that vascular dementia and degenerative dementia such as Alzheimer's disease share similar mechanisms and lesions. ${ }^{25-28}$ Accordingly, the possibility that factors other than extensive small vessel disease such as Alzheimer's disease are involved in the pathogenesis of $\mathrm{CI}$ in $\mathrm{CKD}$ cannot be excluded. In fact, cystatin $C$, an innovative measure of kidney function, is reported to colocalize with $\beta$-amyloid in the brains of patients with Alzheimer's disease. ${ }^{26}$

Numerous cross-sectional and longitudinal reports have correlated CKD with GCI. ${ }^{5-13}$ The REGARDS (Reasons for Geographic and 
Table 6 Contributing factors for confluent white matter lesions (WMLs)

\begin{tabular}{|c|c|c|c|c|c|c|}
\hline & \multicolumn{2}{|c|}{ Univariate analysis } & \multicolumn{4}{|c|}{ Multivariate analysis } \\
\hline & $O R$ & $95 \% \mathrm{Cl}$ & P-value & $O R$ & $95 \% \mathrm{Cl}$ & P-value \\
\hline \multicolumn{7}{|l|}{$W M L$ grade 2 vs. grade 1} \\
\hline Age $65-75$ & 1.61 & $0.74-3.50$ & 0.22 & 1.57 & $0.70-3.50$ & 0.26 \\
\hline Age $>75$ & 2.35 & $1.06-5.22$ & 0.034 & 2.35 & $1.03-5.38$ & 0.041 \\
\hline Sex (male) & 0.49 & $0.27-0.90$ & 0.021 & 0.53 & $0.28-0.98$ & 0.045 \\
\hline Dyslipidemia & 1.79 & $0.93-3.43$ & 0.076 & & & \\
\hline Dipper & 1 & & & & & \\
\hline Non-dipper & 1.16 & $0.52-2.58$ & 0.703 & & & \\
\hline Riser & 2.18 & $0.95-5.01$ & 0.065 & & & \\
\hline 24-h SBP $<125 \mathrm{~mm} \mathrm{Hg}$ & 1 & & & & & \\
\hline 24-h SBP $125-145 \mathrm{~mm} \mathrm{Hg}$ & 1.55 & $0.57-4.21$ & 0.38 & & & \\
\hline \multicolumn{7}{|l|}{$W M L$ grade 3 vs. grade 1} \\
\hline Age $<65$ & 1 & & & 1 & & \\
\hline Age $65-75$ & 0.97 & $0.24-3.84$ & 0.97 & 0.95 & $0.23-3.90$ & 0.95 \\
\hline Age $>75$ & 4.25 & $1.29-13.96$ & 0.016 & 4.11 & $1.21-13.87$ & 0.022 \\
\hline Sex (male) & 0.6 & $0.25-1.45$ & 0.26 & 0.7 & $0.27-1.77$ & 0.45 \\
\hline Hypertension & 1.25 & $0.43-3.62$ & 0.67 & & & \\
\hline Diabetes mellitus & 0.45 & $0.10-2.09$ & 0.31 & & & \\
\hline Dyslipidemia & 1.71 & $0.67-4.40$ & 0.26 & & & \\
\hline Dipper & 1 & & & & & \\
\hline Non-dipper & 1.25 & $0.36-4.28$ & 0.72 & & & \\
\hline
\end{tabular}

Abbreviations: $\mathrm{Cl}$, confidence interval; eGFR, estimated glomerular filtration rate; OR, odds ratio; SBP, systolic blood pressure.

$\mathrm{OR}$ and $95 \% \mathrm{Cls}$ of various covariates for the cognitive impairment group.

Racial Differences in Stroke) study showed that each $10 \mathrm{ml} \mathrm{min}^{-1}$ per $1.73 \mathrm{~m}^{2}$ decrease in eGFR was associated with an $11 \%$ increased prevalence of GCI. ${ }^{5}$ Buchman et al. ${ }^{8}$ prospectively studied 886 elderly without dementia and found that decreased eGFR at baseline was associated with a more rapid rate of cognitive decline. The INVADE study found a significant association between moderate-to-severe CKD at baseline and development of new GCI after following 3679 participants for 2 years (OR, 2.14). ${ }^{9}$ Moreover, the Rancho Bernardo study suggested that CKD makers are helpful to predict the future risk of dementia. ${ }^{13}$

A considerable number of reports have shown the relationship between CKD and small vessel disease independent of vascular risk factors. ${ }^{3,4}$ Decreased GFR is often attributable to renal small vessel disease including glomerular endothelium dysfunction and lipohyalinosis, which are associated with vascular risk factors. ${ }^{29}$ As the vascular supplies to the kidney and brain are similar, renal small vessel disease may also be indicative of the presence of small vessel disease in the brain. ${ }^{30}$ On the other hand, levels of an endogenous inhibitor of nitric oxide synthase, asymmetric dimethylarginine, are increased in patients with impaired kidney function. ${ }^{31}$ Such factors could accelerate extensive small vessel diseases in patients with CKD. It may be safely said that hypertension, especially non-dipping patterns, may cause CKD and CKD may accelerate extensive small vessel diseases those are strongly associated vascular CI. The causal relationship between hypertension, CKD and small vessel disease should be explored further.

The non-dipping status, including non-dippers and risers, was also independently associated with CI. Alterations in autonomic nervous function $^{32}$ and sodium-sensitive essential hypertension ${ }^{33}$ have all been reported to be associated with the non-dipping status. It is uncertain whether non-dipping status represents the primary precipitant for development of CI or it represents the consequence of CI. ${ }^{4,35}$ It should also be noted that the non-dipping status remained significantly associated with CI after adjusting for CKD and extensive small vessel disease. In contrast with previous reports on hypertensive patients, ${ }^{36} \mathrm{a}$ significant relationship between non-dipping status and CKD was not found. It is suspected that patient controls with hypertension ${ }^{36}$ and those with LIs exhibit different characteristics. Active treatment has 
been reported to be associated with reduced risks of dementia and cognitive decline. ${ }^{27}$ Strict night time BP control may be necessary to prevent the progression of $\mathrm{CI}$ in the LI cohort.

The present study showed several limitations. We relied on one serum Cr measurement and did not perform repeat measurements. This was a cross-sectional study and the causal relationship between CKD and GCI could not be determined. The number of patients was small. We were not able to test all cognitive domains, and instead used only the MMSE. Moreover, as we studied LI patients, the possible selection bias and possible influence of infarction on diurnal variation cannot be excluded. ${ }^{34}$ On the other hand, the strengths of the present study included use of a homogeneous cohort of lacunar infarction, precise evaluation of small vessel disease and performance of ABPM.

In conclusion, the majority of patients with GCI in this cohort of patients with LIs may be classified as showing vascular CI correlated with extensive small vessel disease. On the other hand, CKD and hypertensive non-dipper status were associated with GCI independent of traditional vascular risk factors and extensive small vessel disease. Accordingly, CKD may correlate with diseases of GCI other than vascular GCI, such as degenerative GCI. Further studies focusing on the contribution of CKD to CI are warranted. To prevent subsequent progression of cognitive decline, the data indicate that careful consideration for night time BP control and renoprotective treatment may be helpful.

1 Anavekar NS, McMurray JJ, Velazquez EJ, Solomon SD, Kober L, Rouleau JL, White HD, Nordlander R, Maggioni A, Dickstein K, Zelenkofske S, Leimberger JD, Califf RM, Pfeffer MA. Relation between renal dysfunction and cardiovascular outcomes after myocardial infarction. N Engl J Med 2004; 351: 1285-1295.

2 Koren-Morag N, Goldbourt U, Tanne D. Renal dysfunction and risk of ischemic stroke or TIA in patients with cardiovascular disease. Neurology 2006; 67: 224-228.

3 Khatri M, Wright CB, Nickolas TL, Yoshita M, Paik MC, Kranwinkel G, Sacco RL, DeCarli C. Chronic kidney disease is associated with white matter hyperintensity volume: the Northern Manhattan Study (NOMAS). Stroke 2007; 38: 3121-3126.

4 Ikram MA, Vernooij MW, Hofman A, Niessen WJ, van der Lugt A, Breteler MM. Kidney function is related to cerebral small vessel disease. Stroke 2008; 39: 55-61.

5 Kurella Tamura M, Wadley V, Yaffe K, McClure LA, Howard G, Go R, Allman RM, Warnock DG, McClellan W. Kidney function and cognitive impairment in US adults: the Reasons for Geographic and Racial Differences in Stroke (REGARDS) Study. Am J Kidney Dis 2008; 52: 227-234.

6 Hailpern SM, Melamed ML, Cohen HW, Hostetter TH. Moderate chronic kidney disease and cognitive function in adults 20 to 59 years of age: Third National Health and Nutrition Examination Survey (NHANES III). J Am Soc Nephrol 2007; 18: 2205-2213

7 Elias MF, Elias PK, Seliger SL, Narsipur SS, Dore GA, Robbins MA. Chronic kidney disease, creatinine and cognitive functioning. Nephrol Dial Transplant 2009; 24: 2446-2452

8 Buchman AS, Tanne D, Boyle PA, Shah RC, Leurgans SE, Bennett DA. Kidney function is associated with the rate of cognitive decline in the elderly. Neurology 2009; 73 : 920-927.

9 Etgen T, Sander D, Chonchol M, Briesenick C, Poppert H, Förstl H, Bickel H. Chronic kidney disease is associated with incident cognitive impairment in the elderly: the INVADE study. Nephrol Dial Transplant 2009; 24: 3144-3150.

10 Khatri M, Nickolas T, Moon YP, Paik MC, Rundek T, Elkind MS, Sacco RL, Wright CB. CKD associates with cognitive decline. J Am Soc Nephrol 2009; 20: 2427-2432.

11 Tsai CF, Wang SJ, Fuh JL. Moderate chronic kidney disease is associated with reduced cognitive performance in midlife women. Kidney Int 2010; 78: 605-610.

12 Yaffe K, Ackerson L, Kurella Tamura M, Le Blanc P, Kusek JW, Sehgal AR, Cohen D, Anderson C, Appel L, Desalvo K, Ojo A, Seliger S, Robinson N, Makos G, Go AS, Chronic Renal Insufficiency Cohort Investigators. Chronic kidney disease and cognitive function in older adults: findings from the chronic renal insufficiency cohort cognitive study. J Am Geriatr Soc 2010; 58: 338-345.

13 Jassal SK, Kritz-Silverstein D, Barrett-Connor E. A prospective study of albuminuria and cognitive function in older adults: the Rancho Bernardo study. Am J Epidemiol 2010; 171: 277-286.

14 Silbert LC, Howieson DB, Dodge H, Kaye JA. Cognitive impairment risk: white matter hyperintensity progression matters. Neurology 2009; 73: 120-125.

15 Guo X, Pantoni L, Simoni M, Bengtsson C, Björkelund C, Lissner L, Gustafson D, Skoog I. Blood pressure components and changes in relation to white matter lesions: a 32year prospective population study. Hypertension 2009; 54: 57-62.

16 Sander D, Winbeck K, Klingelhöfer J, Conrad B. Extent of cerebral white matter lesions is related to changes of circadian blood pressure rhythmicity. Arch Neurol 2000; 57: 1302-1307.

17 Schwartz GL, Bailey KR, Mosley T, Knopman DS, Jack Jr CR, Canzanello VJ, Turner ST. Association of ambulatory blood pressure with ischemic brain injury. Hypertension 2007; 49: 1228-1234.

18 Yamamoto Y, Akiguchi I, Oiwa K, Hayashi M, Kimura J. Adverse effect of nighttime blood pressure on the outcome of lacunar infarct patients. Stroke 1998; 29: 570-576.

19 Yamamoto Y, Akiguchi I, Oiwa K, Hayashi M, Kasai T, Ozasa K. Twenty-four-hour blood pressure and MRI as predictive factors for different outcomes in patients with lacunar infarct. Stroke 2002; 33: 297-305.

20 Schmidt R, Fazekas F, Kleinert G, Offenbacher H, Gindl K, Payer F, Freidl W, Niederkorn K, Lechner $\mathrm{H}$. Magnetic resonance imaging signal hyperintensities in the deep and subcortical white matter. A comparative study between stroke patients and normal volunteers. Arch Neurol 1992; 49: 825-827.

21 Palatini P, Frigo G, Bertolo O, Roman E, Da Cortà R, Winnicki M. Validation of the A\&D TM-2430 device for ambulatory blood pressure monitoring and evaluation of performance according to subjects' characteristics. Blood Press Monit 1998; 3: 255-260.

22 Imai E, Horio M, Nitta K, Yamagata K, Iseki K, Tsukamoto Y, Ito S, Makino H, Hishida A, Matsuo S. Modification of the Modification of Diet in Renal Disease (MDRD) Study equation for Japan. Am J Kidney Dis 2007; 50: 927-937.

23 Lezak MD, Howieson DB, Loring DW. Neuropsychological Assessment, 4th edn Oxford University Press: Oxford, 2004.

24 O'Bryant SE, Humphreys JD, Smith GE, Ivnik RJ, Graff-Radford NR, Petersen RC, Lucas JA. Detecting dementia with the mini-mental state examination in highly educated individuals. Arch Neurol 2008; 65: 963-967.

25 Sinka L, Kövari E, Gold G, Hof PR, Herrmann FR, Bouras C, Giannakopoulos P. Small vascular and Alzheimer disease-related pathologic determinants of dementia in the oldest-old. J Neuropathol Exp Neurol 2010; 69: 1247-1255.

26 Gold G, Giannakopoulos P, Herrmann FR, Bouras C, Kövari E. Identification of Alzheimer and vascular lesion thresholds for mixed dementia. Brain 2007; 130: 2830-2836.

27 Forette F, Seux ML, Staessen JA, Thijs L, Babarskiene MR, Babeanu S, Bossini A, Fagard R, Gil-Extremera B, Laks T, Kobalava Z, Sarti C, Tuomilehto J, Vanhanen H, Webster J, Yodfat Y, Birkenhäger WH. The prevention of dementia with antihypertensive treatment: new evidence from the Systolic Hypertension in Europe (Syst-Eur) study. Systolic Hypertension in Europe Investigators. Arch Intern Med 2002; 162: 2046-2052.

28 Yaffe K, Lindquist K, Shlipak MG, Simonsick E, Fried L, Rosano C, Satterfield S, Atkinson $H$, Windham BG, Kurella-Tamura M. Cystatin $C$ as a marker of cognitive function in elders: findings from the health ABC study. Ann Neurol 2008; 63: 798-802.

29 Endemann DH, Schiffrin EL. Endothelial dysfunction. J Am Soc Nephrol 2004; 15: 1983-1992.

30 Ito S, Nagasawa T, Abe M, Mori T. Strain vessel hypothesis: a viewpoint for linkage of albuminuria and cerebro-cardiovascular risk. Hypertens Res 2009; 32: 115-121.

31 Pikula A, Böger RH, Beiser AS, Maas R, DeCarli C, Schwedhelm E, Himali JJ, Schulze F, Au R, Kelly-Hayes M, Kase CS, Vasan RS, Wolf PA, Seshadri S. Association of plasma ADMA levels with MRI markers of vascular brain injury: Framingham offspring study. Stroke 2009; 40: 2959-2964.

32 Grassi G, Seravalle G, Quarti-Trevano F, Dell'Oro R, Bombelli M, Cuspidi C, Facchetti R, Bolla G, Mancia G. Adrenergic, metabolic, and reflex abnormalities in reverse and extreme dipper hypertensives. Hypertension 2008; 52: 925-931.

33 Uzu T, Kazembe FS, Ishikawa K, Nakamura S, Inenaga T, Kimura G. High sodium sensitivity implicates nocturnal hypertension in essential hypertension. Hypertension 1996; 28: 139-142.

34 Yamamoto Y, Akiguchi I, Oiwa K, Satoi H, Kimura J. Diminished nocturnal blood pressure decline and lesion site in cerebrovascular disease. Stroke 1995; 26 : 829-833.

35 Yamamoto Y, Akiguchi I, Oiwa K, Hayashi M, Imai K. Twenty-four-hour blood pressure changes in the course of lacunar disease. Cerebrovasc Dis 2001; 11: 100-106.

36 Fukuda M, Mizuno M, Yamanaka T, Motokawa M, Shirasawa Y, Nishio T, Miyagi S, Yoshida A, Kimura G. Patients with renal dysfunction require a longer duration until blood pressure dips during the night. Hypertension 2008; 52: 1155-1160. 